\title{
KARAKTERISTIK SIFAT MEKANIS BAJA LATERIT TERHADAP PROSES PENGEROLAN
}

\author{
Roy Hasudungan, Erwin Siahaan, Rosehan dan Bintang \\ Jurusan Teknik Mesin, Fakultas Teknik Universitas Tarumanagara, LIPI-Metalurgi \\ e-mail: royhasudungan2013@gmail.com
}

\begin{abstract}
Abstrak: Pemanfaatan sumber daya alam di indonesia merupakan salah satu hal yang harus dilakukan karena yang kita ketahui Indonesia memiliki banyak sekali sumber daya yang melimpah dan harus diolah untuk mendapatkan sesuatu yang berguna bagi kehidupan sehari-hari dan bermanfaat bagi kehidupan seluruh warga Indonesia. Baja laterit merupaknan baja yang didapat dari pemurrnian dan pengecoran nikel pig iron. Tujuan dari penelitian ini ialah untuk mengetahui nilai kekerasan baja laterit serta mengetahui struktur mikro pada baja laterit, adapun cara untuk mengetahui proses tersebut ialah dengan cara mencor baja laterit tersebut dengan dicampur dengan zat lainnya, lalu setelah proses pengecoran dilakukan proses pengerolan dengan hot rolling dengan temperatur $900{ }^{\circ} \mathrm{C}$ dengan bermacam reduksi yang bertujuan untuk mengetahui nilai kekerasan dan peruabhan struktur mikro pada setiap reduksi yang terjadi. Kemudian setelah dialkukan proses pengerolan maka dilakukan proses pengujian kekerasan dan metalography,dan untuk memudahkan proses pengujian tersebut maka specimen dipotong dengan panjang $2 \mathrm{~cm}$ lalu specimen tersebut dimounting dengan menggunakan resin.
\end{abstract}

\section{Kata Kunci : iron, laterit, hot rolling, vickers, microhardness, metalography}

\begin{abstract}
Utilization of natural resources in Indonesia is one of the things that must be done because we know Indonesia has a lot of abundant resources and must be processed to get something useful for everyday life and benefit the lives of all citizens of Indonesia. laterite steel is a steels which could be obtained by purifying nickel pig iron. The purpose of this study was to determine the value of the steel hardness laterite, and knowing steel microstructure on laterite, to figure the process, we need to cast the steel and mix it with the another substances,and after the casting process is done with a hot rolling process with temperature of $900{ }^{\circ} \mathrm{C}$ with various reduction which aims to determine the value of hardness and to understand the transformation of the microstructure. After the rolling process is carried out then metalography process is proceed. to facilite the casting process, the specimen was cut to the length of $2 \mathrm{~cm}$ and mounted using a resin.
\end{abstract}

Keywords : iron, laterit, hot rolling, vickers, microhardness, metalography.

\section{LATAR BELAKANG}

Kekayaan alam di Indonesia sangat banyak dan melimpah luas dengan terbukti dari SabangMerauke banyak terdapat daerah-daerah penambangan dari tambang mineral, tambang sumber daya energi, dan tambang daya panas bumi. Hal ini menyebabkan Indonesia menjadi salah satu negara penghasil tambang terbesar di dunia. Salah satu hasil tambang yang banyak dihasilkan berupa mineral meliputi besi, nikel, mangan, tembaga, dan lain-lain. Jenis besi yang didapatkan dari hasil tambang dapat berupa tiga jenis, meliputi besi primer, besi laterit, dan pasir besi.

Banyak peneliti yang melakukan eksplorasi untuk meningkatkan hasil tambang baik dari segi jumlah produksi maupun kualitas dari hasi tambang tersebut. Hal ini juga terjadi dalam penambangan jenis besi laterit. Besi laterit memiliki kandungan besi yang rendah dengan kandungan logam-logam pengotor yang tinggi seperti nikel, krom, kobal, mangan, dan kandungan air yang tinggi. Hal ini yang menyebabkan kualitas dari biji laterit menurun untuk dijadikan bahan mentah untuk diproduksi lebih lanjut.

Baja laterit dapat ditingkatkan kualitasnya dengan membersihkan kandungan pengotornya dan juga dipadu ulang dengan baja murni yang mempunyai kualitas yang baik. Penelitian kali ini untuk meningkatkan kualitas dari baja laterit. selanjutnya dilakukan pengujian berdasarkan sifat mekanis meliputi uji kekerasan (hardness test), dan struktur mikro (metalography). Tujuan dilakukan penelitian ini untuk meningkatkan kualitas dari baja laterit agar dapat langsung diproses menjadi bahan setengah jadi (ingot) ataupun bahan jadi dengan nilai ekonomis yang lebih baik. 


\section{Identifikasi masalah}

Baja laterit yang di dapat dari pemurnian dan pengecoran nikel pig iron. Setelah proses pengecoran dan pengerolan dilakukan uji mekanis yang meliputi, uji kekerasan (hardness test), dan pengamatan struktur mikro (metalography).

\section{Batasan Masalah}

Dalam penelitian ini, dikarenakan materi penelitian cukup luas maka dilakukan pembatasan masalah, meliputi:

a. Material yang digunakan sebagai bahan dasar adalah baja laterit.

b. Proses pengerolan dilakukan dengan reduksi paling tinggi yaitu 50\%.

c. Melakukan uji kekerasan (hardness test) dengan metode Vickers untuk mendapatkan nilai kekerasan pada baja laterit.

d. Melakukan pengamatan struktur mikro (metalography), dari baja laterit.

\section{Perumusan masalah}

Melakukan proses pengerolan dengan reduksi tertinggi yaitu 50\% laterit untuk mengetahui sifat mekanis baja laterit meliputi uji kekerasan (hardness test), dan struktur mikro (metalography) pada baja laterit.

\section{Tujuan penelitian}

Tujuan dilakukan penelitian ini adalah:

a. Untuk medapatkan nilai kekerasan (hardness value) dari baja laterit.

b. Untuk menganalisa dan mengamati struktur mikro (metalography) dan uji kekerasan (hardness test).

c. Untuk mengetahui kekerasan baja laterit dalam setiap reduksi sampai reduksi tertinggi yaitu $50 \%$.

Diagram alir langkah-langkah penyelesaian masalah diberikan pada Gambar 1.

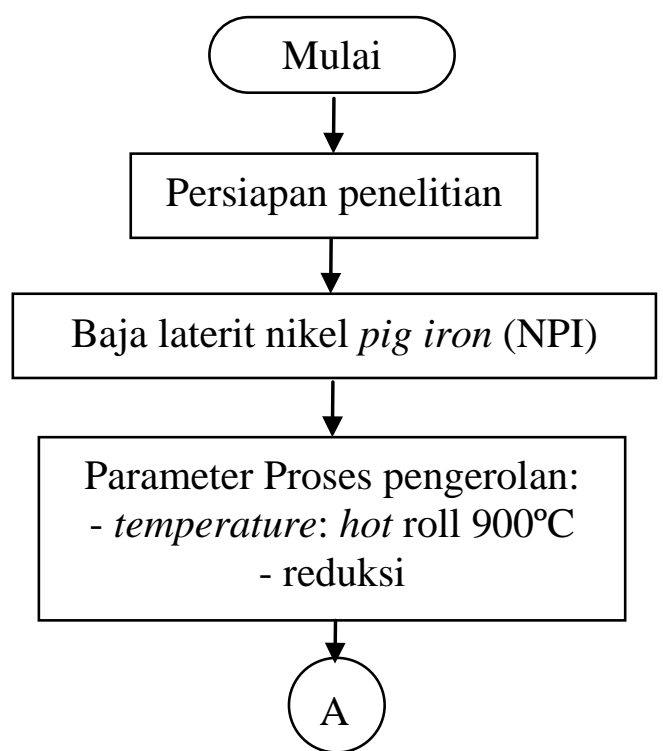

Gambar 1. Diagram alir penelitian 
Lanjutan Gambar 1. Diagram alir penelitian

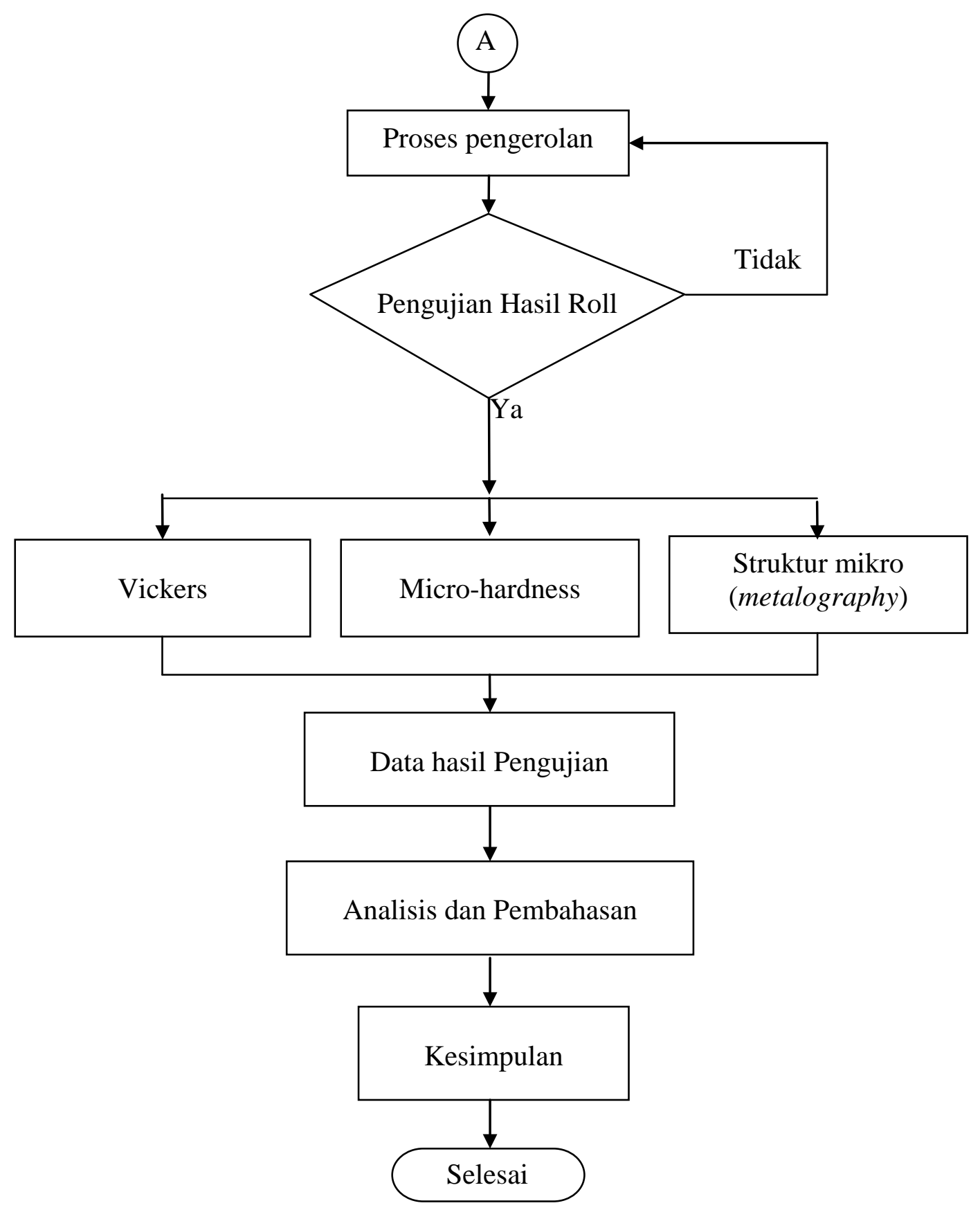

\section{Prosedur Penelitian}

Mengambil baja laterit yang sudah dilakukan proses pengecoran lalu dilakukan proses reduksi berupa proses rolling dengan variasi reduksi dan reduksi tertinggi yaitu 50\%. Setelah melakukan proses prngerollan maka dilakukan pegujian berupa uji tarik (tensile stergth), uji kekerasan (hardness test), dan uji melaografi(metalography test).

\section{Bahan dan peralatan yang digunakan}

Untuk mencapai hasil yang objektif dalam penelitian ini maka bahan yang digunakan merupakan baja laterit yang sudah dilakukan proses pengecoran.

Peralatan yang digunakan sebagai berikut:

- Amplas

- Gergaji besi 
- palu

- Kuas.

- Sarung tangan.

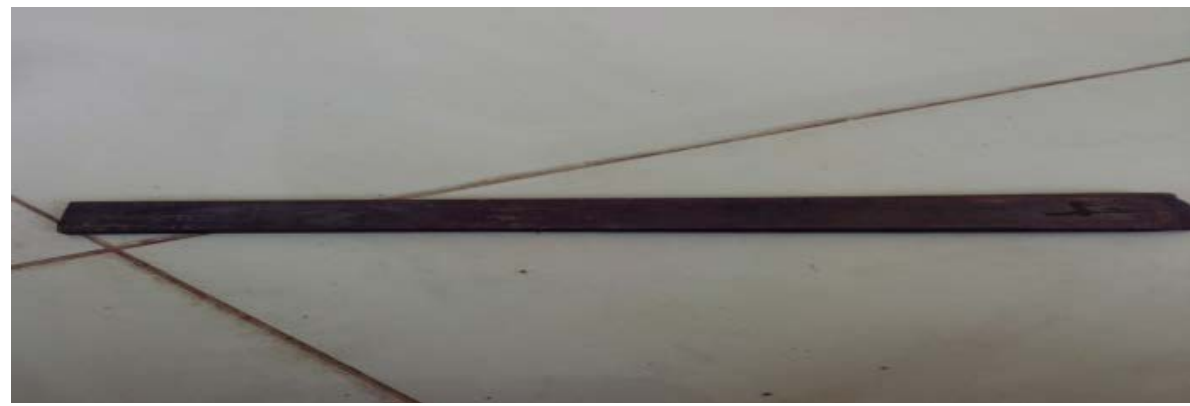

Gambar 2. Baja laterit yang sudah dilakukan proses pengerolan

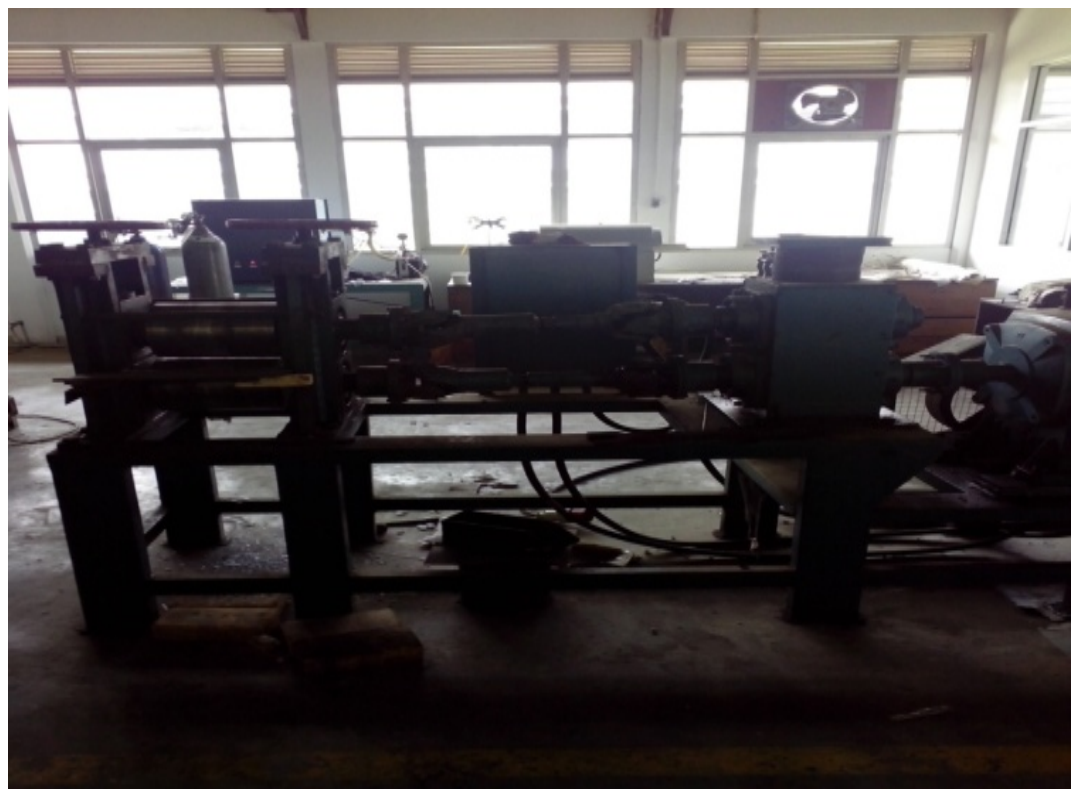

Gambar 3. Mesin rolling dua tingkat

\section{HASIL PENGUJIAN}

Setelah proses pemotongan pada specimen maka specimen dilakukan proses mounting dengan menggunakan resin dan katalis sebagai bahan,setelah dilakukan maka tahap selanjutnya ialah menguji sampel dengan uji kekerasan dengan metode Vickers dan Microhardness, setelah dilakukan proses uji kekerasan maka tahap selanjutnya ialah pengamatan metalografi.

Tabel 1. Uji kekerasan Vickers

\begin{tabular}{|c|c|c|c|c|c|c|}
\hline \multirow[b]{2}{*}{ No } & \multicolumn{2}{|c|}{ Reduksi } & \multicolumn{3}{|c|}{ Pengujian } & \multirow[b]{2}{*}{$\begin{array}{c}\text { Rata-rata } \\
\text { (HV) }\end{array}$} \\
\hline & Sampel & $\begin{array}{c}\text { Reduksi } \\
\text { (\%) }\end{array}$ & $\begin{array}{c}1 \\
(\mathrm{HV})\end{array}$ & $\begin{array}{c}2 \\
(\mathrm{HV})\end{array}$ & $\begin{array}{c}3 \\
(\mathrm{HV})\end{array}$ & \\
\hline 1 & Sampel 1 & 0 & 299 & 204 & 286 & 263 \\
\hline 2 & Sampel 2 & 5 & 286 & 208 & 345 & 279 \\
\hline 3 & Sampel 3 & 10 & 302,5 & 204 & 341 & 282 \\
\hline 4 & Sampel 4 & 15 & 247 & 206 & 341 & 264 \\
\hline 5 & Sampel 5 & 20 & 257 & 193,5 & 252 & 234 \\
\hline 6 & Sampel 6 & 25 & 246 & 192 & 349 & 262 \\
\hline 7 & Sampel 7 & 30 & 236 & 192 & 313 & 247 \\
\hline
\end{tabular}


Lanjutan Tabel 1. Uji kekerasan Vickers

\begin{tabular}{ccccccc}
\hline \multirow{2}{*}{ No } & \multicolumn{2}{c}{ Reduksi } & \multicolumn{3}{c}{ Pengujian } & \multirow{2}{*}{$\begin{array}{c}\text { Rata-rata } \\
(\mathrm{HV})\end{array}$} \\
\cline { 2 - 6 } & Sampel & $\begin{array}{c}\text { Reduksi } \\
(\%)\end{array}$ & $\begin{array}{c}1 \\
(\mathrm{HV})\end{array}$ & $\begin{array}{c}2 \\
(\mathrm{HV})\end{array}$ & $\begin{array}{c}3 \\
(\mathrm{HV})\end{array}$ & \\
\hline 8 & Sampel 8 & 35 & 208 & 195 & 299 & 234 \\
9 & Sampel 9 & 40 & 206 & 186,5 & 293 & 228 \\
10 & Sampel 10 & 45 & 202 & 193,5 & 249 & 214 \\
11 & Sampel 11 & 50 & 232 & 195 & 371 & 266 \\
\hline
\end{tabular}

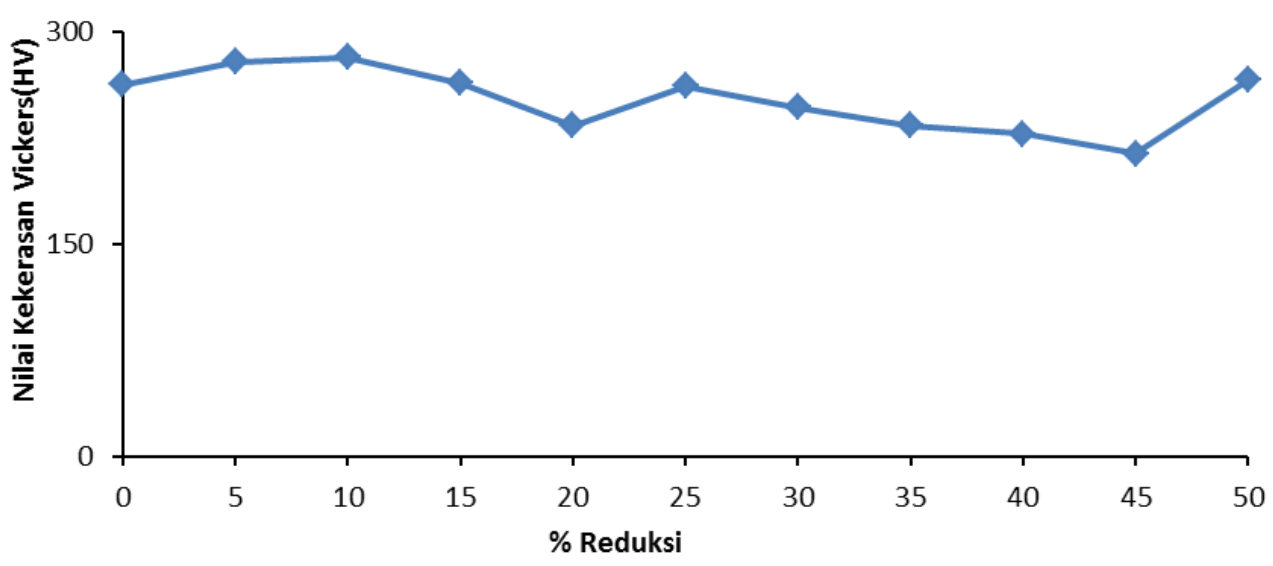

Gambar 4. Grafik Uji Kekerasan Vickers

Tabel 2. Uji kekerasan Microhardness

\begin{tabular}{ccccccc}
\hline No & Sampel & $\begin{array}{c}\text { Reduksi } \\
(\%)\end{array}$ & $\begin{array}{c}1 \\
(\mathrm{HV})\end{array}$ & $\begin{array}{c}2 \\
(\mathrm{HV})\end{array}$ & $\begin{array}{c}3 \\
(\mathrm{HV})\end{array}$ & $\begin{array}{c}\text { Rata-rata } \\
(\mathrm{HV})\end{array}$ \\
\hline 1 & Sampel 1 & 0 & 311,6 & 296,4 & 307,1 & 305 \\
2 & Sampel 2 & 5 & 295,3 & 280,3 & 294,3 & 290 \\
3 & Sampel 3 & 10 & 262,9 & 270,9 & 339,3 & 291 \\
4 & Sampel 4 & 15 & 272,2 & 304,9 & 283,2 & 287 \\
5 & Sampel 5 & 20 & 285,2 & 251 & 289,2 & 275 \\
6 & Sampel 6 & 25 & 264,3 & 252,3 & 302,1 & 273 \\
7 & Sampel 7 & 30 & 245,5 & 250,3 & 296,5 & 264 \\
8 & Sampel 8 & 35 & 252,5 & 238,5 & 294,3 & 262 \\
9 & Sampel 9 & 40 & 251,3 & 237,5 & 290,6 & 260 \\
10 & Sampel 10 & 45 & 247,3 & 236,5 & 246,3 & 243 \\
11 & Sampel 11 & 50 & 247,5 & 238,3 & 349,5 & 278 \\
\hline
\end{tabular}

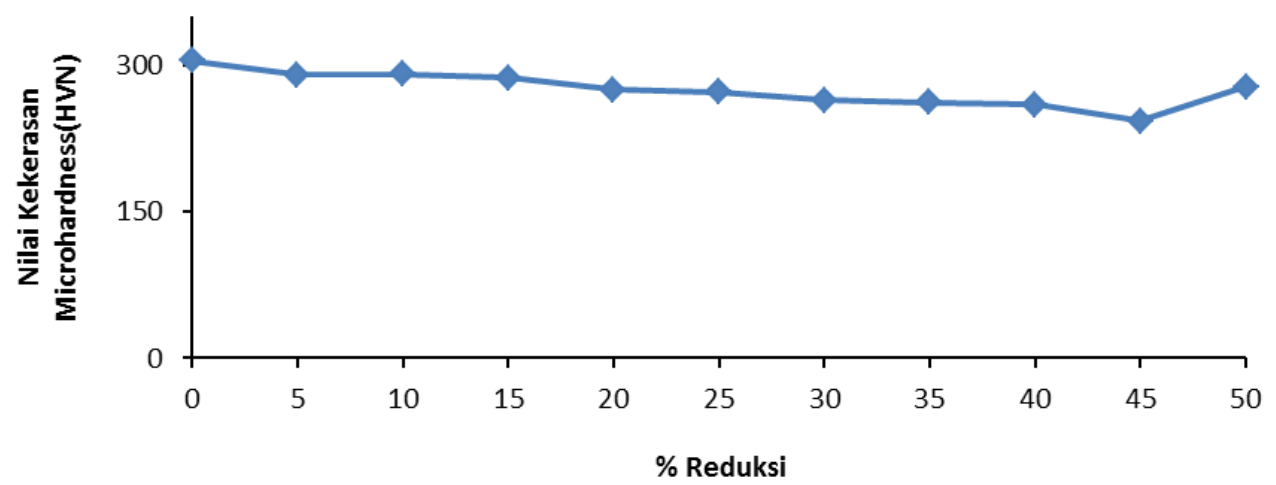

Gambar 5. Grafik Uji Kekerasan Microhardness 

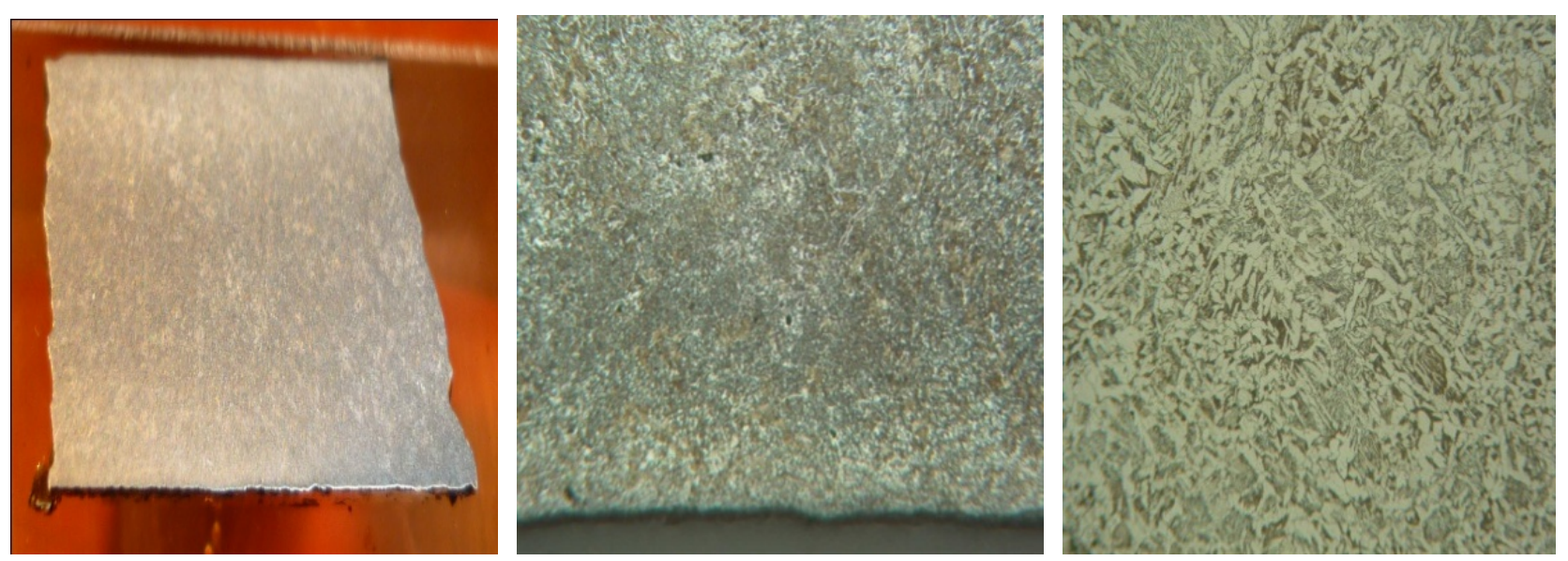

Gambar 6. Foto sampel 1 yang belum direduksi
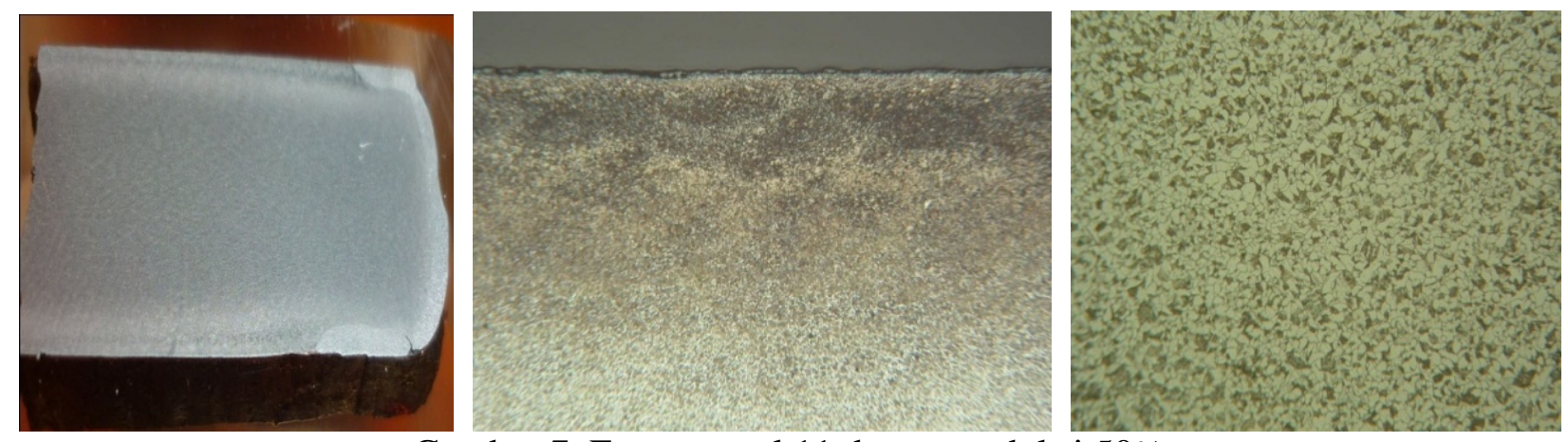

Gambar 7. Foto sampel 11 dengan reduksi 50\%

\section{KESIMPULAN}

- Pada uji kekerasan dengan metode vickers nilai kekerasan tertinggi terjadi di sampel 3 dengan nilai rata-rata 282 dengan reduksi $10 \%$ dan nilai rata-rata terendah pada uji kekerasan Vickers terjadi pada sampel 10 dengan nilai rata-rata 214 dengan reduksi $45 \%$.

- Pada uji kekerasan dengan metode microhardness dengan beban 0,49N nilai kekerasan tertinggi terjadi di sampel 11 dengan nilai rata-rata kekerasan 43 dengan reduksi 50\% dan nilai rata-rata terendah pada uji kekerasan microhardness terjadi pada sampel 10 dan 8 dengan nilai rata-rata 39 dengan reduksi $10 \%$ dan $45 \%$.

- Pada uji kekerasan dengan metode microhardness dengan beban1,96N nilai kekerasan tertinggi terjadi di sampel 1 dengan nilai rata-rata kekerasan 305 belum tereduksidan nilai rata-rata terendah pada uji kekerasan microhardness terjadi pada sampel 10 dengan nilai rata-rata 243 dengan reduksi $45 \%$.

- Pengamatan metalography yang dilakukan terhadap sampel baja laterit setiap reduksinya memiliki struktur yang berbeda dimana pada baja laterit yang belum tereduksi sampai reduksi 25\%memiliki struktur mikro ferrit dan pearlite, mulai terjadi timbul strukuur bainite terjadi pada sampel baja laterit yang direduksi 30\% dan 35\%,dan pada sampel baja laterit dengan reduksi 40\%-50\% terjadi perubahan struktur mikro dari bainite menjadi pearlite seutuhnya.

\section{SARAN}

Pada proses pemotongan sampel baja laterit dilakukan secara manual dengan menggunakan gergaji diakrenakan sampel tidak boleh terlalu panas agar tidak merubah struktur mikro baja laterit, kemudian pada proses metalography dilakukan pengamplasan permukaan dengan baik agar permukaan baja laterit rata dan bisa di uji serta dilakukan pengamatan. 


\section{DAFTAR PUSTAKA}

[1]. Ylldırım, H., Turan, A. and Yücel, O., (2012), Nickel Pig Iron (NPI) Production From Domestic La Teritic Nickel Ores Using Induction Furnace, International Iron \& Steel Symposium, 02-04 April 2012, Karabük, Türkiye.

[2]. Sani H. 2008. Bijih Laterit. [terhubung berkala] http://one.indoskripsi.com (19 Maret 2009).

[3]. Kim, J., Dodbiba, G., Tanno, H., Okayaa, K., Matsuo, S., Fujita, T., (2010), Calcination of Low-Grade Laterite for Concentration of $\mathrm{Ni}$ by Magnetic Separation, Minerals Engineering,288 